\title{
Frontier-based techniques in measuring hospital efficiency in Iran: a systematic review and meta-regression analysis
}

\author{
Aliasghar A Kiadaliri ${ }^{1,2,3^{*}}$, Mehdi Jafari ${ }^{4}$ and UIf-G Gerdtham ${ }^{1,3,5}$
}

\begin{abstract}
Background: In recent years, there has been growing interest in measuring the efficiency of hospitals in Iran and several studies have been conducted on the topic. The main objective of this paper was to review studies in the field of hospital efficiency and examine the estimated technical efficiency (TE) of Iranian hospitals.

Methods: Persian and English databases were searched for studies related to measuring hospital efficiency in Iran. Ordinary least squares (OLS) regression models were applied for statistical analysis. The PRISMA guidelines were followed in the search process.

Results: A total of 43 efficiency scores from 29 studies were retrieved and used to approach the research question. Data envelopment analysis was the principal frontier efficiency method in the estimation of efficiency scores. The pooled estimate of mean TE was $0.846( \pm 0.134)$. There was a considerable variation in the efficiency scores between the different studies performed in Iran. There were no differences in efficiency scores between data envelopment analysis (DEA) and stochastic frontier analysis (SFA) techniques. The reviewed studies are generally similar and suffer from similar methodological deficiencies, such as no adjustment for case mix and quality of care differences. The results of OLS regression revealed that studies that included more variables and more heterogeneous hospitals generally reported higher TE. Larger sample size was associated with reporting lower TE.

Conclusions: The features of frontier-based techniques had a profound impact on the efficiency scores among Iranian hospital studies. These studies suffer from major methodological deficiencies and were of sub-optimal quality, limiting their validity and reliability. It is suggested that improving data collection and processing in Iranian hospital databases may have a substantial impact on promoting the quality of research in this field.
\end{abstract}

Keywords: Technical efficiency, Meta-regression, Data envelopment analysis, Stochastic frontier analysis, Iran

\section{Background}

According to the World Health Organization (WHO), the percentage of health expenditure out of gross domestic production (GDP) in Iran increased from $4.6 \%$ in 2000 to $5.5 \%$ in 2008 [1]. As hospitals are considered the main consumer of health care resources in any health care system [2], the issue of containing costs without loss of quality has been high on the health care agenda in most countries. In this regard, improving efficiency is

\footnotetext{
* Correspondence: aliasghar.ahmad_kiadaliri@med.lu.se

'Division of Health Economics, Department of Clinical Sciences-Malmö, Lund University, Malmö University Hospital, CRC, Entrance 72, House 28, Plan 10, Room 027, 20502 Malmö, Sweden

${ }^{2}$ Department of Health Management and Economics, School of Public

Health, Tehran University of Medical Sciences, Tehran, Iran

Full list of author information is available at the end of the article
}

considered a main option in planning to contain hospital costs [3].

In 2006, bed occupancy rate and average length of stay for the hospitals affiliated to the Iranian Ministry of Health were $70 \%$ and 3.38 days, respectively [4]. In comparison with international figures, these figures indicate technical inefficiency in hospitals in Iran and there is much scope for improvement. This inefficiency has attracted the attention of policy-makers, resulting in measures such as formation of a Board of Trustees in hospitals, implementation of performance-based budgeting, establishing a hospital information system and maintenance management [5]. In response to this policy interest, a considerable body of literature has emerged to measure the efficiency of Iranian hospitals in recent years. As these studies are mainly

\section{Biomed Central}


policy-oriented, and aim to assist policy-making, the estimated efficiency scores should be robust to model specifications [6] or policy-makers should at least be aware of the effects of these specifications on estimated scores.

Efficiency can be assessed in term of different concepts including technical, scale, price and allocative efficiency [7]. Efficiency concept used in our review is technical efficiency which is a measure based on work of Farrell [8]. A hospital is technically efficient when it is producing the maximum amount of output from a given amount of input, or alternatively producing a given output with minimum quantities of inputs. Thus, when a hospital is technically efficient, it operates on its production frontier [9].

Different methods have been applied to measure hospital efficiency around the world, the frontier-based methods, mainly data envelopment analysis (DEA) and stochastic frontier analysis (SFA), being the most common [10]. The frontier-based methods compare hospitals' actual performance against an estimated efficient frontier. It is well documented that the features of frontier-based methods have an important impact on the estimated efficiency scores [6,10-16]. Selection of input and output variables is among the main features which significantly affect the results of these models $[17,18]$. In addition, the selection of input and output variables in these studies may negatively affect individual and population health (e.g. using length of stay as output may encourage hospitals to admit patients with less complicated disease [18]).

On the output side, there are two main types of outputs: health services (e.g. number of outpatient visits, number of inpatient visits, etc.) and health outcomes (e.g. postoperative mortality rate, blood pressure control, etc.) [10]. In practice, due to lack of data, most studies use health services as a proxy for health outcomes [10]. These studies implicitly assume that health services lead to health outcomes and no difference is measured between hospitals in providing health services [6]. However, if this assumption does not hold, then using health services as a proxy for health outcomes is problematic [15]. For example, if a hospital provides health services of low quality which lead to adverse events and re-admission, then using inpatient days as output would mean rewarding this hospital for its bad performance. Moreover, this approach generally ignores hospitals' functions other than curative care (e.g. prevention, research and educational functions) [18]. In addition, many earlier studies in developed countries and most studies in developing countries naively used raw counts in capturing the health services as output. This can lead to bias if there are case-mix differences between hospitals $[6,18]$.

Regarding input, there are three main input categories: human (e.g. physicians, nurses), capital (e.g. beds), and consumable resources (e.g. consumed drugs). These variables are generally measured as counts (number of physicians, nursing hours) or as monetary values (e.g. salaries, annual expenditure of capital) [6]. In addition, features such as sample size, homogeneity of units under study, ratio between sample size and number of input and output variables, and input/output returns-to-scale orientation also affect the estimated efficiency scores [6,10-16].

Although there are several systematic reviews of health care efficiency studies in the literature [10,17-22], to our knowledge only one previous study [6] has used metaregression to quantify the impact of modelling choices on the estimated efficiencies in reviewed studies. As all of these studies focused on English-language publications, many of non-English studies were overlooked in these systematic reviews. Moreover, some recent Iranian studies published in English were not included in these systematic reviews. Hence, the contribution of the current study is to systematically review hospital efficiency studies in Iran, published in Persian and English, and quantify the impact of modelling choices on the estimated efficiency scores using meta-regression.

\section{Methods}

Search strategy

A literature review by AAK and MJ was independently conducted by searching international (EconLit, Pubmed, Scopus, Embase, and Web of Science) and national Iranian (SID, Magiran) databases in September 2011 with an update performed in January and November 2012. Search terms included efficiency, hospital, productivity, DEA, SFA, and Iran. The PRISMA guidelines [23] were followed in the search process.

\section{Selection of studies}

Five inclusion criteria were applied: (1) the report included mean technical efficiency (TE) or data needed to calculate it; (2) the unit of analysis was the hospital; (3) the data required for analysis were available (by access to the full text of the publication or by request from the author); (4) the study's observations were limited to hospitals within the boundaries of Iran; (5) the report was published in Persian or English.

The initial search resulted in 1,432 documents. After excluding duplicates and non-relevant studies, 29 articles were selected for full text examination. The reference lists of these 29 documents were manually searched. In total, 29 studies passed the exclusion criteria for the systematic review. In addition to peer-reviewed articles we also included MSc and PhD dissertations and theses and conference proceedings in the analysis. Figure 1 shows the process of study selection.

\section{Data extraction}

For each study, data on the year and language of publication, number of hospitals included in the study, estimation methods, activity of the hospitals (teaching and/ 


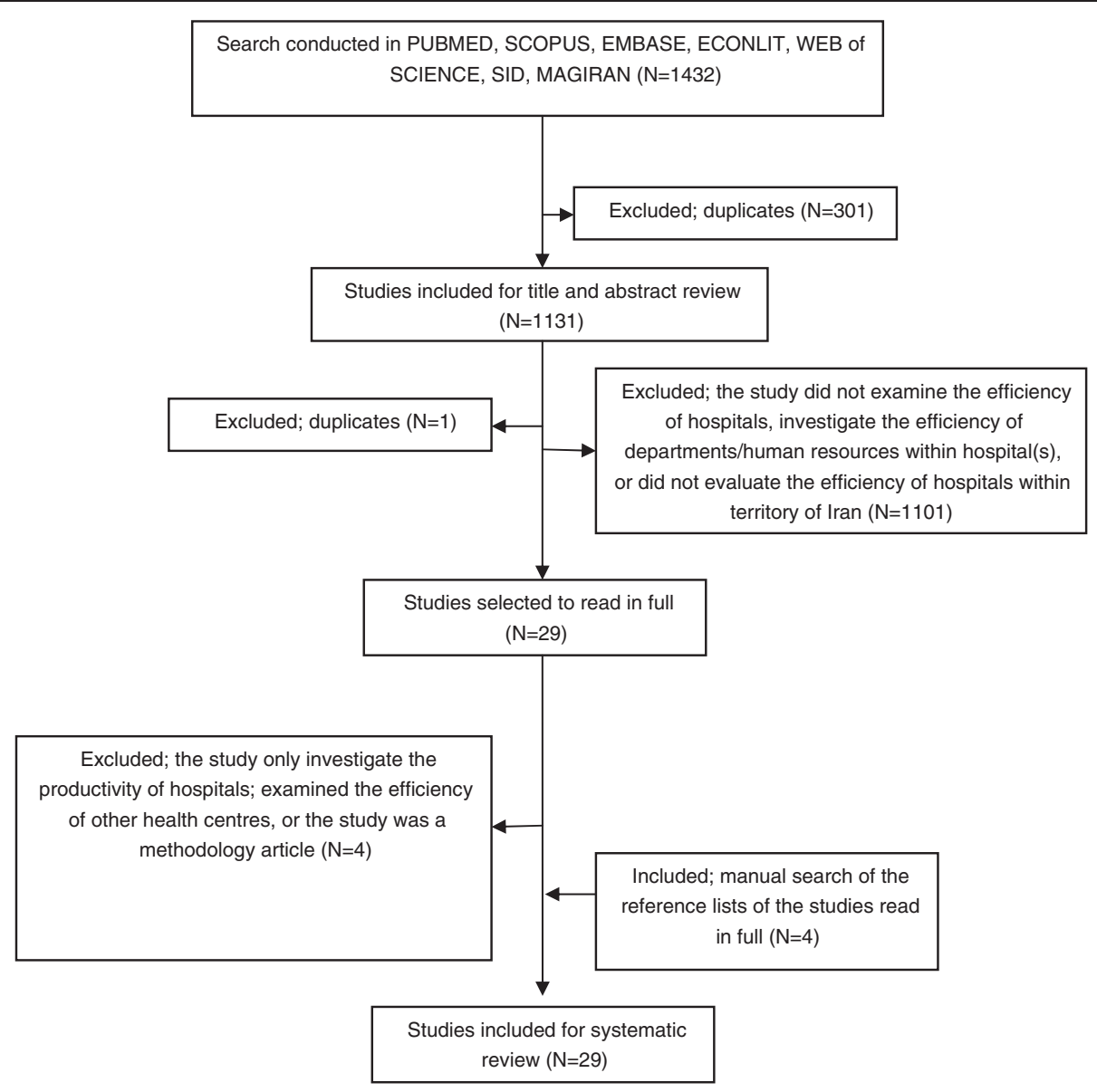

Figure 1 Flow diagram of literature search.

or non-teaching), ownership status of the hospitals (government, private, social security organization, charity and military), type of hospital (general and/or specialty), data years, geographical coverage of the study (single or multiple provinces), number of variables (inputs and outputs) used in the model and estimated efficiency scores were extracted.

\section{Statistical analysis}

Two types of analyses were applied: univariate and multivariate. In the univariate analysis, the mean TE was compared using Wilcoxon's rank-sum test based on different features of the studies. In the multivariate analysis, the mean TE was used as dependent variable in the meta-regression. Based on literature and model specifications in the primary studies, we used the number of variables (dimension), sample size (number of hospitals), estimation method (SFA v. DEA), orientation (input v. output), percentage of teaching hospitals, publication period and heterogeneity in the sample in terms of type, activity, location and ownership as explanatory variables. We included these variables because previous studies showed that heterogeneity across the sample can affect the estimated efficiency scores [15]. Moreover, as all the studies which used panel data reported a separate score for each year, we averaged these estimates and calculated a pooled TE and included a dummy variable in our meta-regression as pooled $\mathrm{v}$. single estimate.

The linear-log function, as recommended by Nguyen and Coelli [6], was used in the following estimation:

$$
\begin{aligned}
M T E= & \beta_{0}+\beta_{1}(S F A)+\beta_{2}(\text { Pooled })+\beta_{3} \ln (\text { Size }) \\
& +\beta_{4} \ln (\text { Dimension })+\beta_{5}(\text { Output-orient }) \\
& +\beta_{6}(\text { Heterogeneity })+\beta_{7}(\text { Publication period }) \\
& +\beta_{8}(\% \text { of teaching hospitals })
\end{aligned}
$$

where MTE is the mean TE. For the estimation method, the ordinary least square (OLS) method was used as it is a consistent estimator and is preferred to the Tobit model in efficiency analyses [24,25]. Moreover, as there were no efficiency scores equal to 1 in our dataset, the Tobit regression produces the same estimates as OLS regression [26]. The standard errors were corrected for 
Table 1 The characteristics of studies included in the meta-regression analysis

\begin{tabular}{|c|c|c|c|c|c|c|c|c|c|c|c|}
\hline No. & Author(s) & $\begin{array}{l}\text { Publication } \\
\text { year }\end{array}$ & $\begin{array}{l}\text { Publication } \\
\text { language }\end{array}$ & Data year & $\begin{array}{l}\text { No. of } \\
\text { hospitals }\end{array}$ & $\begin{array}{l}\text { Proportion } \\
\text { of teaching } \\
\text { hospitals (\%) }\end{array}$ & $\begin{array}{l}\text { Number of } \\
\text { input/output } \\
\text { variables }\end{array}$ & Estimation method & Province & $\begin{array}{l}\text { Software used } \\
\text { to assess efficiency }\end{array}$ & $\begin{array}{l}\text { Number of } \\
\text { estimates }\end{array}$ \\
\hline 1 & Abolhalaj et al. [30] & 2011 & Persian & 2007 & 122 & 45.08 & $4 / 2$ & DEA & NA & DEAP 2.1 & 6 \\
\hline 2 & Ahmadkiadaliri et al. [31] & 2011 & English & 2006 & 19 & 21.05 & $2 / 4$ & DEA & Khuzestan & DEAP 2.1 & 1 \\
\hline 3 & Akbari et al. [32] & 2012 & Persian & $2005-2008$ & 20 & NA & $4 / 3$ & DEA & East Azerbaijan & DEAP 2.1 & 1 \\
\hline 4 & Alemtabriz \& Imanipour [33] & 2009 & Persian & 2005-2007 & 16 & 68.75 & $4 / 5$ & DEA & Tehran & LINDO & 1 \\
\hline 5 & Ardakani et al. [34] & 2009 & Persian & 2004-2006 & 12 & 33.33 & $3 / 3$ & DEA & Yazd & LINDO & 1 \\
\hline 6 & Asadi et al. [35] & 2012 & Persian & 2008 & 13 & 38.46 & $3 / 3$ & DEA & Yazd & DEAP 2.1 & 1 \\
\hline 7 & Askari et al. [36] & 2012 & Persian & 2001-2009 & 13 & 38.46 & $4 / 3$ & DEA & Yazd & DEAP 2.1 & 1 \\
\hline 8 & Farzianpour et al. [37] & 2012 & English & 2008-2010 & 16 & 100.00 & $3 / 3$ & DEA & Tehran & GAMS & 1 \\
\hline 9 & Goudarzi [38], Ghaderi et al. [39]* & 2006,2007 & Persian & $2000-2004$ & 26 & 42.31 & $4 / 4,4 / 1$ & DEA, SFA & Tehran & DEAP 2.1, Frontier 4.1 & 2 \\
\hline 10 & Goudarzi et al. [40] & 2012 & Persian & $2001-2007$ & 13 & 30.77 & $4 / 5,4 / 1$ & DEA, SFA & Lorestan & DEAP 2.1, Frontier 4.1 & 2 \\
\hline 11 & Hajialiafzali et al. [41] & 2007 & English & 2002 & 53 & 0.00 & $4 / 4$ & DEA & NA & DEASOFT-V1 & 1 \\
\hline 12 & Hatam [42] & 2008 & English & 1996 & 18 & 0.00 & $2 / 4$ & DEA & NA & NA & 1 \\
\hline 13 & Hatam et al. [43] & 2010 & English & 2005-2006 & 21 & NA & $3 / 5$ & DEA & Fars & GAMS & 1 \\
\hline 14 & Pourmohammadi [44] Hatam et al. [45]* & 2009, 2012 & Persian \& English & $2006-2008$ & 64 & 0.00 & $4 / 4,4 / 1$ & DEA, SFA & NA & WIN4DEAP, Frontier 4.1 & 2 \\
\hline 15 & Ilbeigi et al. [46] & 2012 & Persian & 2009 & 17 & NA & $2 / 3$ & DEA & Khorasan Razavi & DEAP 2.1 & 1 \\
\hline 16 & Jandaghi et al. [47] & 2010 & English & 2008 & 8 & NA & $2 / 3,3 / 3,5 / 3,4 / 3$ & DEA & Qom & WIN4DEAP & 4 \\
\hline 17 & Marnani et al. [48] & 2012 & English & 2010 & 23 & 56.52 & $1 / 4$ & DEA & Tehran & WIN4DEAP & 1 \\
\hline 18 & Pourreza et al. [49] & 2009 & Persian & 1996-2006 & 12 & 83.33 & $4 / 4$ & DEA & Tehran & DEAP 2.1 & 1 \\
\hline 19 & Rahimi et al. [50] & 2012 & Persian & 2009 & 23 & 17.39 & $3 / 2$ & DEA & West Azerbaijan & DEAP 2.1 & 1 \\
\hline 20 & Rezapoor \& Asefzadeh [51] & 2009 & Persian & 1998-2007 & 4 & 100.00 & $2 / 5$ & DEA & Qazvin & DEAP 2.1 & 1 \\
\hline 21 & Sabermahani et al. [52] & 2009 & Persian & 2007 & 13 & 23.08 & $4 / 3$ & DEA & Kerman & DEAP 2.1 & 1 \\
\hline 22 & Sajadi et al. [53] & 2009 & Persian & 2005-2006 & 23 & 13.04 & $5 / 5$ & DEA & Isfahan & DEAP 2.1 & 2 \\
\hline 23 & Salehzadeh \& Ketabi [54] & 2011 & Persian & 2007 & 8 & 37.50 & $2 / 2$ & DEA & Qom & WIN4DEAP, DEA-Master & 1 \\
\hline 24 & Shahhoseini et al. [55] & 2011 & English & 2008 & 12 & 33.33 & $4 / 5$ & DEA & NA & DEAP 2.1 & 1 \\
\hline 25 & Sheikhzadeh et al. [56] & 2012 & English & 2005 & 11 & 45.45 & $4 / 3$ & DEA & East Azerbaijan & DEAP 2.1 & 1 \\
\hline 26 & Ahmad Kiadaliri [57]* & 2005 & Persian & 1996-2003 & 8 & 62.50 & $4 / 4,4 / 1$ & DEA & Tehran & DEAP 2.1 & 2 \\
\hline 27 & Najafi [58]* & 2008 & Persian & $2000-2006$ & 12 & 33.33 & $2 / 2$ & DEA & Ardebil, Tehran & DEAP 2.1 & 1 \\
\hline 28 & Kazemi et al. [59]* & 2009 & Persian & $2006-2008$ & 11 & 18.18 & $2 / 2$ & DEA & $\begin{array}{l}\text { Southern Khorasan, } \\
\text { Northern Khorasan, } \\
\text { Khorasan Razavi }\end{array}$ & DEAP 2.1 & 2 \\
\hline 29 & Zarei [60]* & 2000 & Persian & 1999 & 57 & 68.42 & $6 / 4$ & DEA & Tehran & NA & 1 \\
\hline
\end{tabular}

*These are grey literature including thesis and conference presentations. Goudarzi and Pourmohammadi published their results of DEA application as a journal article [39,45]. 
clustering when estimates were derived from the same study and also for heteroskedasticity [27]. Data were analysed using STATA statistical package, version 11 (StataCorp LP, College Station, TX, USA).

\section{Sensitivity analysis}

To assess the robustness of the results, a sensitivity analysis was conducted excluding studies that were not journal articles. Moreover, to check the influence of each study on the results, a sensitivity analysis was performed omitting each study in turn and then estimating the summary effect of the remaining studies.

\section{Results}

A total of 43 estimated efficiency scores from 29 studies were retrieved and included in the meta-regression analysis. Table 1 shows the characteristics of studies included in our analysis. There was a 5-year lag between the first and second applications of frontier-based methods in measuring hospital efficiency in Iran. After the second study using this method, in 2005, there was at least one publication per year on the topic, with a peak in publications in 2012 (Figure 2). The years of data used in the estimation ranged from 1996 to 2010. Sample size ranged from four to 122, with a median of 16 hospitals per model. The dimension (inputs and outputs) ranged from four to ten, with a median of six variables per model. Data envelopment analysis was applied in all studies, with three studies using both DEA and SFA to estimate the efficiency scores. Most studies (25 out of 29) were carried out in a single province of Iran. Among the provinces, the hospitals in Tehran (Iran's capital) were naturally studied more than the other hospitals. DEAP version 2.1 [28] and FRONTIER version 4.1 [29] were the main software packages used to estimate DEA and SFA models, respectively. All studies were inputoriented and two studies used output orientation in a sensitivity analysis.

In terms of ownership status of the hospitals, 20 out of 29 studies exclusively estimated the efficiency of government hospitals. Among the remaining studies, government hospitals were included in six studies. Regarding the hospitals' activity, 23 studies included both teaching and nonteaching hospitals in the sample, while five studies included only non-teaching hospitals and one included only teaching hospitals. In terms of types of hospital, in 17 studies the sample included both general and specialty hospitals while twelve studies included only general hospitals.

Regarding input and output variables included in the studies, while human and capital resources were included in almost all studies (one study included the number of staffed beds as a single input), only four studies included consumable resources as an input variable. In most studies (93.1\%), the input variables were measured as counts. In six studies, human resources were aggregated into one category. The number of staffed beds was used as the main proxy for capital resources. Generally a combination of number of physicians, number of nurses, number of other human resources and number of staffed beds were selected as the input variables.

Almost all studies (96.55\%) considered only health services as the output variable. In three studies, annual hospital income was also included as an output variable. These variables were typically included as raw counts, such as

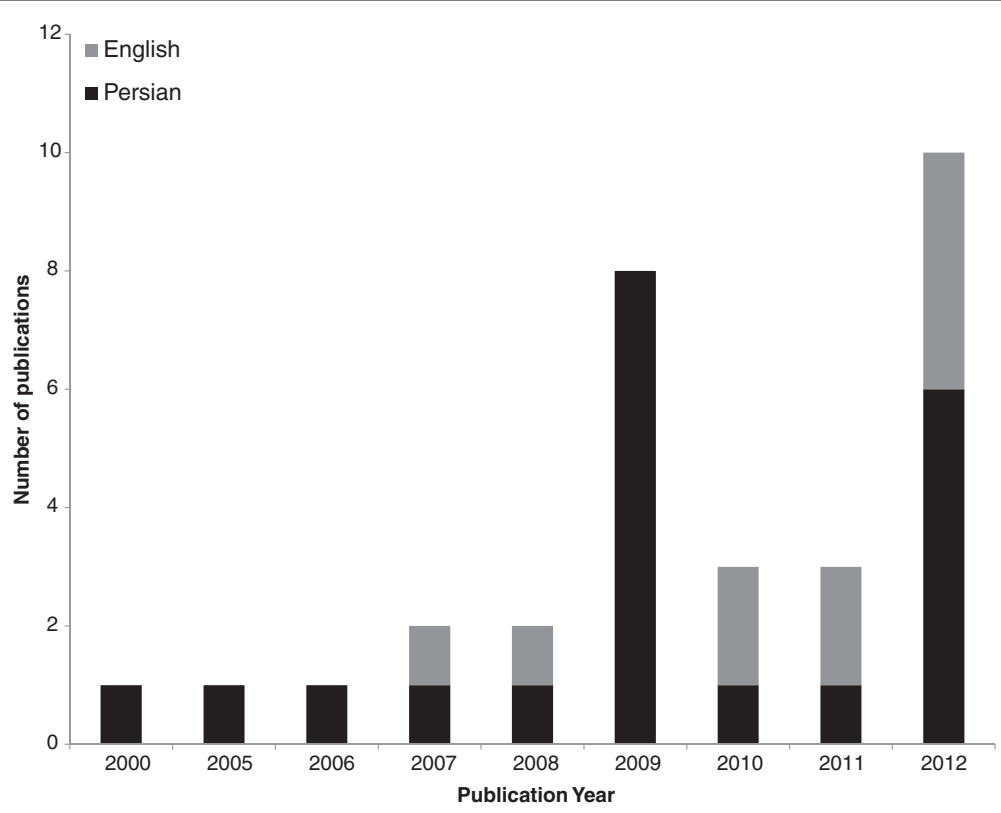

Figure 2 Distribution of studies by year and language. 
Table 2 Quality assessment of studies included in the meta-regression analysis

\begin{tabular}{|c|c|c|c|c|c|c|c|c|c|}
\hline No. & $\begin{array}{l}\text { Adjustment } \\
\text { for quality } \\
\text { of care? }\end{array}$ & $\begin{array}{l}\text { Adjustment } \\
\text { for teaching } \\
\text { activities? }\end{array}$ & $\begin{array}{l}\text { Assess the } \\
\text { determinants } \\
\text { of efficiency? }\end{array}$ & $\begin{array}{l}\text { Sensitivity } \\
\text { analysis? }\end{array}$ & $\begin{array}{l}\text { Ratio of size } \\
\text { to dimension } \geq 3 \text { ? }\end{array}$ & $\begin{array}{l}\text { Homogeneity in type of } \\
\text { hospital (general/specialty)? }\end{array}$ & $\begin{array}{l}\text { Homogeneity in activity } \\
\text { (teaching/non-teaching)? }\end{array}$ & $\begin{array}{l}\text { Homogeneity } \\
\text { in hospital } \\
\text { ownership status? }\end{array}$ & $\begin{array}{l}\text { Homogeneity } \\
\text { in location (same/ } \\
\text { multiple province)? }\end{array}$ \\
\hline 1 & No & No & No & No & Yes (in 5 out of 6 estimates) & Yes (in 5 out of 6 estimates) & Yes (in 5 out of 6 estimates) & Yes & No \\
\hline 2 & No & No & No & No & Yes & Yes & No & Yes & Yes \\
\hline 3 & No & No & Yes & No & No & Yes & No & Yes & Yes \\
\hline 4 & No & No & No & No & No & Yes & No & Yes & Yes \\
\hline 5 & No & No & No & No & No & No & No & Yes & Yes \\
\hline 6 & Yes & Yes & No & No & No & No & No & Yes & Yes \\
\hline 7 & No & No & Yes & No & No & No & No & Yes & Yes \\
\hline 8 & No & No & No & No & No & No & Yes & Yes & Yes \\
\hline 9 & No & No & Yes & No & Yes & No & No & Yes & Yes \\
\hline 10 & No & No & Yes & No & No & No & No & Yes & Yes \\
\hline 11 & No & - & No & No & Yes & No & Yes & Yes & No \\
\hline 12 & No & - & No & No & Yes & No & Yes & Yes & No \\
\hline 13 & No & No & No & No & No & Yes & No & Yes & Yes \\
\hline 14 & No & - & No & No & Yes & No & Yes & Yes & No \\
\hline 15 & No & No & No & No & Yes & Yes & No & Yes & Yes \\
\hline 16 & No & No & No & Yes & No & No & No & No & Yes \\
\hline 17 & No & No & No & No & Yes & No & No & Yes & Yes \\
\hline 18 & No & No & Yes & No & No & No & No & Yes & Yes \\
\hline 19 & No & No & No & No & Yes & No & No & Yes & Yes \\
\hline 20 & No & No & No & No & No & Yes & No & Yes & Yes \\
\hline 21 & No & No & Yes & No & No & Yes & No & Yes & Yes \\
\hline 22 & No & No & No & Yes & No & Yes & No & Yes & Yes \\
\hline 23 & No & No & No & No & No & No & No & No & Yes \\
\hline 24 & No & No & No & No & No & No & Yes & No & Yes \\
\hline 25 & No & No & No & No & No & No & No & No & Yes \\
\hline 26 & No & No & No & Yes & No & Yes & No & Yes & Yes \\
\hline 27 & No & No & No & No & Yes & Yes & No & Yes & No \\
\hline 28 & No & No & Yes & Yes & No & No & No & No & No \\
\hline 29 & No & No & No & No & Yes & No & No & No & Yes \\
\hline
\end{tabular}


inpatient days and number of surgeries, without adjusting to the differences in the severity of treated cases. Teaching and research activities of hospitals were not accounted for in most of the studies (only one study captured these).

Table 2 gives a quality assessment of the studies included in the analysis and shows aspects which might bias the estimated efficiency scores. Most of these aspects (seven out of nine), especially adjustment for quality of care and capturing hospitals' teaching activities, were weakly handled in most of the studies. Only in about $40 \%$ of the studies was the rule of thumb of three observations per variable [61] satisfied. In seven studies, univariate statistical analysis $(t-$ test) was applied to assess the relationship between efficiency scores and some environmental factors (Table 2, column 4). The sensitivity analysis through specifying models with different mix of variables to test the robustness of results was applied in only four studies.

Table 3 shows the mean TE according to different characteristics of the studies. The pooled estimate of mean TE was $0.846( \pm 0.134)$. This suggests that hospitals could improve their performance by about $15 \%$. The maximum and minimum of efficiency scores were 0.436 and 0.996, respectively (not shown). This indicates a considerable variation in the efficiency scores between the different studies performed in Iran. The studies that used SFA for estimation reported lower efficiency scores compared with studies using DEA, but this difference was not statistically significant. Studies that included hospitals from a single province reported higher efficiency scores compared with cross-province studies. Larger sample size and lower number of input and output variables in the models were associated with lower efficiency scores. Figures $3 \mathrm{a}-\mathrm{b}$ present the relation between mean TE and the number of variables (dimension) and sample size for each model.

Table 4 presents the results of the meta-regression analysis. Different models were applied and based on F-test results and R-square, model 7 was selected as the final model. Everything else equal, larger sample size was associated with lower efficiency scores. Evaluating the marginal effect of sample size in the median sample size of 16 yielded a marginal effect of -0.006 . On the other hand, there was a positive association between dimension and the efficiency scores. The effect of dimension on estimated efficiency scores was more substantial than that of size. In the sample median of six variables, the marginal effect of dimension was equal to 0.03 . While heterogeneity was associated with higher efficiency scores, only heterogeneity in type of hospital was statistically significant. Studies that were published from 2010 onwards reported, on average, 0.07 lower efficiency score compared with studies published before this year.

When we included only the estimations from the journal articles in the sensitivity analysis, publication before
Table 3 Mean technical efficiency (TE) by the variables used in the analysis

\begin{tabular}{|c|c|c|c|}
\hline Variable & No. of estimates & Mean TE ( \pm SD) & p-value \\
\hline \multicolumn{4}{|l|}{ Method } \\
\hline SFA & 3 & $0.739( \pm 0.084)$ & 0.060 \\
\hline DEA & 40 & $0.854( \pm 0.134)$ & \\
\hline \multicolumn{4}{|l|}{ Orientation } \\
\hline Input & 41 & $0.843( \pm 0.137)$ & 0.885 \\
\hline Output & 2 & $0.890( \pm 0.013)$ & \\
\hline \multicolumn{4}{|l|}{ Estimation } \\
\hline Pooled & 20 & $0.872( \pm 0.083)$ & 0.679 \\
\hline Single & 23 & $0.822( \pm 0.164)$ & \\
\hline \multicolumn{4}{|l|}{ Heterogeneity in location } \\
\hline Yes & 13 & $0.766( \pm 0.176)$ & 0.015 \\
\hline No & 30 & $0.880( \pm 0.095)$ & \\
\hline \multicolumn{4}{|l|}{ Heterogeneity in activity } \\
\hline Yes & 32 & $0.863( \pm 0.120)$ & 0.290 \\
\hline No & 11 & $0.797( \pm 0.165)$ & \\
\hline \multicolumn{4}{|c|}{ Heterogeneity in ownership } \\
\hline Yes & 10 & $0.901( \pm 0.066)$ & 0.307 \\
\hline No & 33 & $0.829( \pm 0.145)$ & \\
\hline \multicolumn{4}{|c|}{ Heterogeneity in type of hospital } \\
\hline Yes & 26 & $0.863( \pm 0.131)$ & 0.109 \\
\hline No & 17 & $0.819( \pm 0.137)$ & \\
\hline \multicolumn{4}{|l|}{ No. of hospitals ${ }^{a}$} \\
\hline$\leq 16$ & 23 & $0.892( \pm 0.073)$ & 0.070 \\
\hline$>16$ & 20 & $0.793( \pm 0.167)$ & \\
\hline \multicolumn{4}{|c|}{ No. of input and output variables } \\
\hline$\leq 6$ & 24 & $0.791( \pm 0.151)$ & 0.001 \\
\hline$>6$ & 19 & $0.914( \pm 0.060)$ & \\
\hline \multicolumn{4}{|c|}{ No. of hospitals:No. of variables ratio } \\
\hline$<3$ & 26 & $0.894( \pm 0.071)$ & 0.017 \\
\hline$\geq 3$ & 17 & $0.771( \pm 0.172)$ & \\
\hline \multicolumn{4}{|l|}{ Publication year } \\
\hline$\leq 2009$ & 19 & $0.885( \pm 0.068)$ & 0.406 \\
\hline$>2009$ & 24 & $0.815( \pm 0.164)$ & \\
\hline \multicolumn{4}{|l|}{ Type of publication } \\
\hline Journal article & 35 & $0.842( \pm 0.144)$ & 0.662 \\
\hline Other & 8 & $0.861( \pm 0.082)$ & \\
\hline Overall & 43 & $0.846( \pm 0.134)$ & - \\
\hline
\end{tabular}

a Divided based on median value.

2010 was no longer significant and heterogeneity in type of hospital was significant at the $10 \%$ level. Moreover, another sensitivity analysis showed that no single study had a significant effect on our results.

\section{Discussion}

In this analysis, we reviewed studies that measured TE of hospitals in Iran and quantified the impact of model specifications on the reported efficiency scores using meta- 


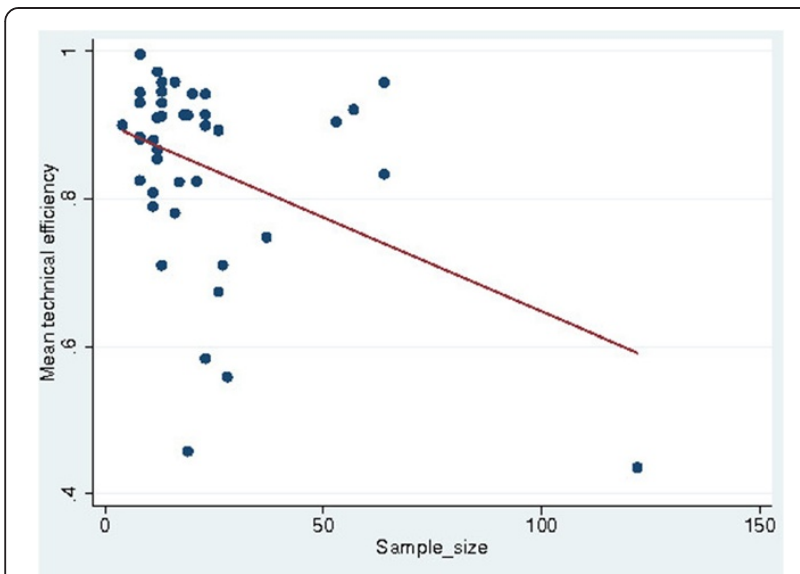

(a)

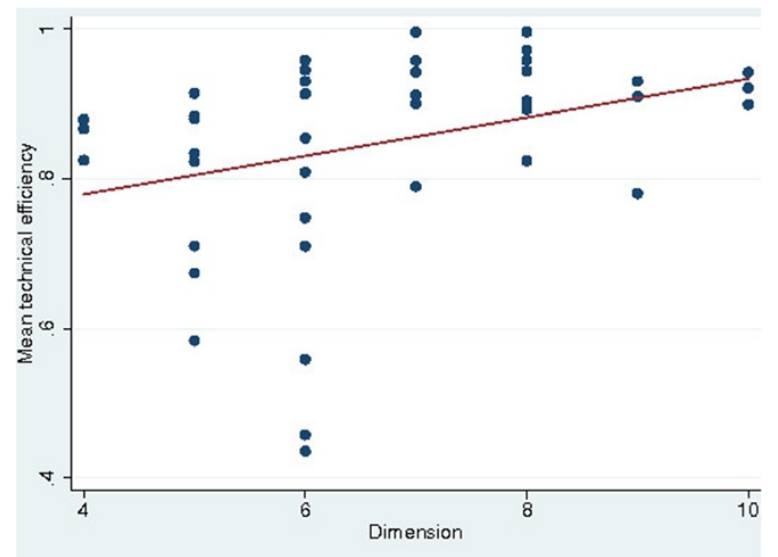

(b)

Figure 3 The relation between the mean technical efficiency and (a) size and (b) dimension. regression analysis based on 43 extracted observations from 29 different studies. To our knowledge, this is the first attempt to quantify the effect of model choice on hospitals' efficiency scores in a developing country such as Iran. There has been a growing trend in recent years to measure hospitals' efficiency using frontier-based techniques, especially DEA. The findings from the review study also show that many studies suffer from major methodological problems and are of sub-optimal quality.

We found that DEA was the dominant method of measurement of hospital efficiency in Iran. This is in line with previous international findings [20,21]. Ability to handle multiple inputs and outputs in different units of measurement is the main explanation for this [20]. In addition, similar to previous reviews $[6,19]$, input orientation was the main choice in these studies, suggesting that hospital managers have more control over inputs than over outputs.

Aggregation of input categories, focus on curative function of hospitals, no adjustment for differences in case mix and quality of care between hospitals, small sample size, little adjustment for heterogeneity in the sample, and no attempt to examine the causes of inefficiency, as well as no attempt to evaluate the misspecification in applied models, and little attempt to analyse the relationship between the efficiency scores and environmental factors are some of the main, and common, limitations of these studies. This raises many issues of validity, usefulness and generalizability of these studies in Iran.

It seems that the lack of data is the main reason for these limitations among Iranian studies. As has been argued by Afzali et al. [18], Iranian hospital databases suffer from data limitation regarding a broad range of hospital functions (e.g. preventive care, health promotion) and

Table 4 Results of the meta-regression analysis

\begin{tabular}{|c|c|c|c|c|c|c|c|c|}
\hline & Model 1 & Model 2 & Model 3 & Model 4 & Model 5 & Model 6 & Model 7 & Model 8 \\
\hline Ln (Size) & $-0.088^{*}$ & -0.081 & $-0.077^{* *}$ & $-0.083^{* *}$ & $-0.080^{*}$ & $-0.094^{* *}$ & $-0.097^{* *}$ & $-0.101^{* * *}$ \\
\hline Ln (Dimension) & $0.197^{* * *}$ & $0.174^{* * *}$ & $0.172^{* *}$ & $0.195^{* * *}$ & $0.200^{* * *}$ & $0.216^{* * *}$ & $0.198^{* * *}$ & $0.204^{* * *}$ \\
\hline SFA & & -0.065 & & & & & & \\
\hline Pooled & & 0.060 & & & & & & \\
\hline Output orientation & & 0.035 & & & & & & \\
\hline Heterogeneity in location & & & -0.033 & & & & & \\
\hline Heterogeneity in activity & & & & 0.020 & & & & \\
\hline Heterogeneity in ownership status & & & & & 0.041 & & & \\
\hline Heterogeneity in type of hospital & & & & & & $0.069^{*}$ & $0.072^{* *}$ & $0.069^{*}$ \\
\hline Published from 2010 onwards & & & & & & & $-0.071^{* *}$ & $-0.076^{* *}$ \\
\hline Percentage of teaching hospitals in sample & & & & & & & & -0.077 \\
\hline Constant & $0.731 * * *$ & $0.667 * * *$ & $0.754^{* * *}$ & $0.705^{* * *}$ & $0.691^{* * *}$ & $0.669^{* * *}$ & $0.750^{* * *}$ & $0.779^{* * *}$ \\
\hline $\mathrm{N}$ & 43 & 43 & 43 & 43 & 43 & 43 & 43 & 36 \\
\hline R-squared & 0.290 & 0.336 & 0.298 & 0.294 & 0.305 & 0.354 & 0.423 & 0.456 \\
\hline
\end{tabular}

SFA $=$ stochastic frontier analysis.

${ }^{* * *},{ }^{* *}$ and ${ }^{*}$ shows the $1 \%, 5 \%$ and $10 \%$ significance level, respectively; standard errors adjusted for clustered observations. 
quality of care. Hence, improving data collection and processing in Iranian hospital databases is a critical step in promoting quality in hospital efficiency studies. On the other hand, a few studies have tried to deal with these limitations, for example using the ratio of the number of major surgeries to the total number of surgeries to capture the complexity of surgical operations [41], or the ratio of published scientific articles to the total number of physicians to capture the hospitals' research function [35]. This implies that available data are not always used appropriately by researchers in Iran, possibly due to a limited understanding of hospitals' functions among researchers.

The results of the meta-regression show that there were no significant differences in the estimated efficiency scores between SFA and DEA applications. There is no agreement on the impact of parametric v. nonparametric method on the efficiency scores in the literature. Kontodimopoulos et al. [12] reported lower efficiency scores for DEA compared with SFA, while Gannon [62] found the opposite. On the other hand, Nguyen and Coelli [6] did not find any statistically significant differences between these two methods.

The associations between sample size and dimension and the estimated efficiency scores are in line with previous studies $[6,16]$. It is argued that small sample size may cause sparsity problems, meaning that a hospital can be deemed efficient just because of lack of any comparator. In other words, as sample size increases, the estimated efficient frontier asymptotically approaches the true frontier and more observations are deemed inefficient compared with a smaller sample size [16]. In the same way, everything else equal, increasing the number of input and output variables in a model raises the sparsity problem [16]. The estimated marginal effect of sample size and dimension in our study may help policy-makers to compare the results of different studies with different sample sizes and dimensions in the country. Including more heterogeneous hospitals in the sample is associated with higher efficiency scores, as previously confirmed by Jacobs et al. [15].

The findings of the current study should, however, be interpreted with caution. As Iranian databases are not well developed, we may have missed some studies. Because only a few studies used SFA, it was not possible to control for the model choices in SFA, such as functional form used for technology structure, distribution of inefficiency components, etc. There are some other explanatory variables (e.g. location of hospital, degree of autonomy) that may affect the estimated efficiency scores of different studies, but the small sample size did not allow us to control for them.

\section{Conclusions}

The findings of the current study show that the methodology choices have an important impact on the estimated efficiency scores, implying that results of these studies should be interpreted and treated with caution. Moreover, the impact of modelling choices on efficiency scores in Iranian hospitals was comparable with that found internationally [6]. The studies included in this review suffer from major methodological deficiencies and are of suboptimal quality, limiting their validity and reliability for policy-making in the country. Hollingworth [9] in his review of the efficiency studies in health care concluded that most studies in this field are of the "have software-will analyse" nature. Our review suggests the same scenario among Iranian studies. Including data on a broader range of hospital functions and quality of care in the Iranian hospital databases, and promoting the knowledge about hospital functions among researchers, as well as making better use of available data, and developing a critical assessment tool to evaluate the quality of efficiency studies are some major steps which should be taken to improve the quality of hospital efficiency studies in Iran and possibly other developing countries.

\section{Competing interests}

The authors declare that they have no competing interests.

\section{Authors' contributions}

AAK participated in the design of the study, literature search, analysis and interpretation, and drafting of the manuscript. MJ participated in the literature search, interpretation and drafting of the manuscript. U-GG participated in the interpretation of data and drafting of the manuscript. All authors read and approved the final manuscript.

\section{Acknowledgement}

We would like to thank all authors who kindly provided the essential data for conducting this research. Moreover, we would like to thank Mrs Parvaneh Heidari and Mrs Maryam Mirmalek for their help and comments.

\section{Author details}

${ }^{1}$ Division of Health Economics, Department of Clinical Sciences-Malmö, Lund University, Malmö University Hospital, CRC, Entrance 72, House 28, Plan 10, Room 027, 20502 Malmö, Sweden. ${ }^{2}$ Department of Health Management and Economics, School of Public Health, Tehran University of Medical Sciences, Tehran, Iran. ${ }^{3}$ Health Economics \& Management, Institute of Economic Research, Lund University, Lund, Sweden. ${ }^{4}$ Department of Health Management and Economics, School of Health Informatics and Management, Iran University of Medical Sciences, Tehran, Iran. ${ }^{5}$ Department of Economics, Lund University, Lund, Sweden.

Received: 14 May 2013 Accepted: 13 August 2013

Published: 15 August 2013

\section{References}

1. World Health Statistics: ; 2011 [http://www.who.int/whosis/whostat/2011/en/]

2. McKee M, Healy J: Hospitals in a Changing Europe. Philadelphia: Open University Press; 2002.

3. Kuntz L, Scholtes S, Vera A: Incorporating efficiency in hospital-capacity planning in Germany. Eur J Health Econ 2007, 8:213-223.

4. World Bank: Islamic Republic of Iran, Health Sector Review, Volume II: Background Sections. The World Bank Group, Human Development Sector, Middle East and North Africa. Washington DC: World Bank; 2007.

5. Jafari M, Rashidian A, Abolhasani F, Mohammad K, Yazdani S, Parkerton P, Yunesian M, Akbari F, Arab M: Space or no space for managing public hospitals; a qualitative study of hospital autonomy in Iran. Int J Health Plann Manage 2011, 26(3):e121-e137. 
6. Nguyen KH, Coelli T: Quantifying the effects of modelling choices on hospital efficiency measures: a meta-regression analysis. Center for Efficiency and Productivity Analysis, Working Paper No. WP07; 2009

7. Ozcan YA: Health care benchmarking and performance evaluation: An assessment using data envalopment analysis (DEA). New York: Springer; 2008.

8. Farrell MJ: The Measurement of Productive Efficiency. J R Stat Soc 1957, 120(3):253-290.

9. Hollingworth B: Non-parametric and parametric applications measuring efficiency in health care. Health Care Manag Sci 2003, 6:203-218.

10. Hussey PS, de Vries H, Romley J, Wang MC, Chen SS, Shekelle PG, McGlynn EA: A systematic review of health care efficiency measures. Health Serv Res 2009, 44(3):784-805.

11. Thiam A, Bravo-Ureta BE, Rivas TE: Technical efficiency in developing country agriculture: a meta-analysis. Agric Econ 2001, 25:235-243.

12. Kontodimopoulos N, Papathanasiou ND, Flokou A, Tountas Y, Niakas D: The impact of non-discretionary factors on DEA and SFA technical efficiency differences. J Mel Syst 2011, 35:981-989.

13. Jacobs R: Alternative methods to examine hospital efficiency: data envelopment analysis and stochastic frontier analysis. Health Care Manag Sci 2001, 4(2):103-115.

14. Mutter RL, Rosko MD, Greene WH, Wilson PW: Translating frontiers into practice: taking the next steps toward improving hospital efficiency. Med Care Res Rev 2011, 68(1 Suppl):3S-19S.

15. Jacobs R, Smith PC, Street A: Measuring Efficiency in Health Care. Cambridge: Cambridge University Press; 2006

16. Pedraja-Chaparro F, Salinas-Jimenez J, Smith P: On the quality of the data envelopment analysis model. Journal of Operational Research Society 1999 50:636-644.

17. Morita H, Avkiran NK: Selecting inputs and outputs in data envelopment analysis by designing statistical experiments. Journal of the Operations Research 2009, 52:163-173.

18. Afzali HH, Moss JR, Mahmood MA: A conceptual framework for selecting the most appropriate variables for measuring hospital efficiency with a focus on Iranian public hospitals. Health Serv Manage Res 2009, 22(2):81-91.

19. O'Neill L, Rauner M, Heidenberger K, Kraus M: A cross-national comparison and taxonomy of DEA-based hospital efficiency studies. Socioecon Plann Sci 2008, 42:158-189.

20. Worthington A: Frontier efficiency measurement in healthcare: a review of empirical techniques and selected applications. Med Care Res Rev 2004, $61(2): 1-36$.

21. Hollingworth $B$ : The measurement of efficiency and productivity of health care delivery. Health Econ 2008, 17:1107-1128.

22. Rosko MD, Mutter RL: Stochastic frontier analysis of hospital inefficiency: a review of empirical issues and an assessment of robustness. Med Care Res Rev 2008, 65:131-166.

23. Moher D, Liberati A, Tetzlaff J, Altman DG: Preferred reporting items for systematic reviews and meta-analyses: the PRISMA statement. PloS Med 2009, 6(7):e1000097.

24. McDonald J: Using least squares and Tobit in second stage DEA efficiency analyses. Eur J Operl Res 2009, 197:792-798.

25. Hoff A: Second stage DEA: Comparison of approaches for modelling the DEA scores. Eur J Operl Res 2007, 181:425-435.

26. Kieschnick R, McCullough BD: Regression analysis of variates observed on $(0,1)$ : percentages, proportions and fractions. Stat Modelling 2003, 3:193-213.

27. Williams RL: A note on robust variance estimation for cluster-correlated data. Biometrics 2000, 56:645-646.

28. Coelli T: A Guide to DEAP Version 2.1: A Data Envelopment Analysis (Computer) Program. CEPA Working Paper 96/08. Australia: University of New England; 1996

29. Coelli T: A Guide to FRONTIER Version 4.1: A Computer Program for Stochastic Frontier Production and Cost Function Estimation. CEPA Working Paper 96/08. Australia: University of New England; 1996.

30. Abolhalaj M, Najafi B, Ahmad Kiadaliri A: Measuring the technical efficiency of hospitals affiliated to medical sciences universities in the country in 2007. [in Persian]. Journal of Teb \& Tazkieh 2011, 19(3):49-61.

31. Ahmadkiadaliri A, Haghparast-Bidgoli $H$, Zarei A: Measuring efficiency of general hospitals in the south of Iran. World Applied Sciences Journal 2011, 13(6):1310-1316

32. Akbari F, Arab M, Keshavarz K, Dadashi A: Technical efficiency analyses in hospitals of Tabriz University of Medical Sciences. [in Persian]. Hosp Q 2012, 11(2):65-75.
33. Alemtabriz A, Imanipour M: Measuring the relative efficiency of hospitals using DEA [in Persian]. Management Perspective 2009, 31:139-157.

34. Ardakani MA, Mirghafouri $H$, Mirfakhrodini $H$, Damaki AM, Momeni $H$ : Evaluating the relative efficiency of public hospitals in Yazd province using DEA. [in Persian]. Journal of Yazd University of Medical Sciences 2009, 17(2):200-208.

35. Asadi M, Mirghafoori H, Arani ZS, Khosravanian H: Qualitative Performance Evaluation of Hospitals Using DEA, Balanced Scorecard and Servqual: A Case Study of General Hospitals of Yazd. [in Persian]. Journal of Shaheed Sadoughi University of Medical Sciences 2012, 18(6):559-569.

36. Askari R, Goudarzi G, Fallahzadeh H, Zarei B, Tafti AD: Efficiency appraisal of Yazd university of medical science hospitals by quantitative approach data envelopment analysis. [in Persian]. Payavard Salamat 2012, 6(3):215-224.

37. Farzianpour F, Hosseini S, Amali T, Hosseini S, Hosseini SS: The evaluation of relative efficiency of teaching hospitals. Am J App/ Sci 2012, 9(3):392-398.

38. Goudarzi G: Determination and Survey of Factors effecting in technical efficiency of hospitals affiliated with IUMS by SFA and DEA methods from 2000 to 2004. [in Persian] M.S. Thesis. Tehran, Iran: Iran University of Medical Sciences; 2006

39. Ghaderi H, Goudarzi G, Gohari M: Determining the technical efficiency of hospitals affiliated to IUMS using DEA through 2000-2004 [in Persian]. J Heal Manag 2007, 26:31-38.

40. Goudarzi G, Imaninasab MH, Jahanmehr N, Rostami K, Omidifar R, Mahooti F: Evaluating the performance of hospitals affiliated to LUMS through 2001-2007. [in Persian]. Payesh 2012, 11(3):295-301.

41. Hajialiafzali H, Moss JR, Mahmood MA: Efficiency measurement for hospitals owned by the Iranian social security organisation. J Med Syst 2007, 31:166-172.

42. Hatam N: The role of Data Envelopment Analysis (DEA) pattern in the efficiency of social security hospitals in Iran. Iran Red Crescent Med J 2008, 10(3):211-217.

43. Hatam N, Moslehi S, Askarian M, Shokrpour N, Keshtkaran A, Abbasi M: The Efficiency of General Public Hospitals in Fars Province, Southern Iran. Iran Red Crescent Med J 2010, 12(2):138-144.

44. Pourmohammadi K: Evaluating the technical efficiency of hospitals owned by social security organisation using DEA through 2006-2008. [in Persian] M.S. Thesis. Shiraz, Iran: Shiraz University of Medical Sciences; 2009.

45. Hatam N, Pourmohammadi K, Keshtkaran A, Javanbakht M, Askarian M: Factors affecting efficiency of social security hospitals in Iran: Data envelopment analysis. HealthMED 2012, 6(6):1961-1968.

46. Ilbeigi A, Kazemi M, Peivandi MT: Relationship between official performance measurement scores and Relative efficiency in general hospitals. [in Persian]. Hosp Q 2012, 11(2):31-44.

47. Jandaghi G, Matin HZ, Doremami M, Aghaziyarati M: Efficiency evaluation of Qom public and private hospitals using data envelopment analysis. European Journal of Economics, Finance and Administrative Sciences 2010, 22:84-93.

48. Marnani AB, Sadeghifar J, Pourmohammadi K, Mostafaie D, Abolhalaj M, Bastani P: Performance assessment indicators: how DEA and Pabon Lasso describe Iranian hospitals' performance. HealthMED 2012, 6(3):791-796.

49. Pourreza A, Goudarzi G, Hedayat H: Determining the technical efficiency of hospitals affiliated with TUMS using DEA through 1996-2006. [in Persian]. The Journal of Public Health School 2009, 7(4):79-86.

50. Rahimi B, Yusefzadeh H, Khalesi N, Valinejadi A, Gozali A, Akbari S, Haghighatfard P: Analysis of the efficiency and optimal consumption of resources in selected hospitals in Urmia province through data envelopment analysis [in Persian]. Journal of Health Administration 2012, 47:91-102.

51. Rezapoor A, Asefzadeh S: Economic efficiency of health care providers affiliated with QUMS through 1998-2007. [in Persian]. Journal of Gilan University of Medical Sciences 2009, 18(71):55-63.

52. Sabermahani A, Goudarzi G, Barooni M, Khakian M: Evaluating the technical efficiency of public hospitals affiliated with KUMS in 2007. [in Persian]. Journal of Kerman University of Medical Sciences 2009, 17(1):59-67.

53. Sajadi H, Karami M, Torkzadeh L, Karimi S, Bidram R: The efficiency of teaching and non-teaching medical centres and public hospitals affiliated with IUMS using DEA through 2005-2006 [in Persian]. Journal of Health Administration 2009, 36:39-46.

54. Salehzadeh R, Ketabi S: Evaluating the relative efficiency of hospitals using DEA and AHP in Qom province. [in Persian]. Health Inf Manag 2011, 8(4):1-10. 
55. Shahhoseini R, Tofighi S, Jaafaripooyan E, Safiaryan R: Efficiency measurement in developing countries: application of data envelopment analysis for Iranian hospitals. Health Serv Manage Res 2011, 24:75-80.

56. Sheikhzadeh Y, Roudsari AV, Vahidi RG, Emrouznejad A, Dastgiri S: Public and Private Hospital Services Reform Using Data Envelopment Analysis to Measure Technical, Scale, Allocative, and Cost Efficiencies. Health Promotion Perspectives 2012, 2(1):28-41.

57. Ahmad Kiadaliri A: Determining the technical efficiency of hospitals affiliated to IUMS using DEA through 1996-2003. [in Persian] M.S. Thesis. Tehran, Iran: Iran University of Medical Sciences; 2005.

58. Najafi B: Employing DEA method to measure the productivity and efficiency in hospitals affiliated with Shahed University and general hospital of Ardebil Province through 1999-2006. [in Persian] M.S. Thesis. Tehran, Iran: Shahed University; 2008.

59. Kazemi Z, Ahmad Kiadaliri A, Haghparast-Bidgoli H: Data envelopment analysis as a method for performance-based budgeting: a case study in the selective hospitals. [in Persian]. In Proceedings of the Third International performance based budgeting conference. Tehran, Iran; 2009.

60. Zarei B: Designing the efficiency evaluation criteria in medical institutions. [in Persian] M.A. Thesis. Tehran, Iran: University of Tehran; 2000.

61. Banker RD, Charnes A, Cooper W, Swarts J, Thomas D: An introduction to data envelopment analysis with some models and their use. Research in Governmental and Non-Profit Accounting 1989, 5:125-163.

62. Gannon B: Testing for variation in technical efficiency of hospitals in Ireland. The Economics and Social Review 2005, 36(3):273-294.

doi:10.1186/1472-6963-13-312

Cite this article as: Kiadaliri et al.: Frontier-based techniques in measuring hospital efficiency in Iran: a systematic review and meta-regression analysis. BMC Health Services Research 2013 13:312.

\section{Submit your next manuscript to BioMed Central and take full advantage of:}

- Convenient online submission

- Thorough peer review

- No space constraints or color figure charges

- Immediate publication on acceptance

- Inclusion in PubMed, CAS, Scopus and Google Scholar

- Research which is freely available for redistribution 